\title{
Ethnicity and sex are strong determinants of diabetes in an urban Western society: implications for prevention
}

Received: 9 August 2004 / Accepted: 12 November 2004 / Published online: 24 February 2005

C) Springer-Verlag 2005

\begin{abstract}
Aims/hypothesis: This study was conducted to investigate the prevalence of diabetes and its association with ethnicity and sex, to identify subgroups at special risk. Methods: We performed a population-based cross-sectional survey of 30- to 67-year-olds in an area of Oslo with low socio-economic status, and collected data using questionnaires, physical examinations and serum analyses for the 2,513 participants (attendance rate 49.3\%). Results: In the age group 30-59 years, mean BMI was 28.5 (95\% CI: 27.5-29.6) for South Asian women, 26.1 (25.9-26.4) for Western women, 26.7 (26.1-27.4) for South Asian men and 27.2 (26.9-27.5) for Western men. The diabetes prevalence rates were $27.5 \%(18.1-36.9)$ for South Asian women, $2.9 \%$ (1.9-3.4) for Western women, $14.3 \%$ (8.020.7) for South Asian men and 5.9\% (4.2-7.5) for Western men. The age-adjusted odds ratio (OR) for diabetes for women vs men was $1.9(0.9-4.1)$ for South Asians, and 0.4 $(0.3-0.6)$ for the Western population $(p<0.001)$. The ageadjusted OR for diabetes for South Asians vs Westerners was $11.0(5.8-21.1)$ for women and 3.0 (1.6-5.4) for men, and after adjustment for WHR the ORs were 7.7 (3.9-15.3) for women and 2.6 (1.4-4.9) for men. After additional adjustments for physical activity, education, body height and fertility for women, the OR was $6.0(2.3-15.4)$ for women
\end{abstract}

\footnotetext{
A. K. Jenum $(\bowtie) \cdot$ S. Graff-Iversen

Norwegian Institute of Public Health, PO Box 4404, Nydalen,

0403 Oslo, Norway

e-mail: anne.karen.jenum@fhi.no

Tel.: 47-23408208

Fax: $+47-22353605$

I. Holme

Norwegian University of Sport and Physical Education, Oslo, Norway
}

A. K. Jenum · K. I. Birkeland

The Diabetes Research Centre, Aker University Hospital, Oslo, Norway and $1.9(0.9-4.0)$ for men. Conclusions/interpretation: The alarmingly high prevalence of diabetes among South Asian women in Norway needs further investigation, as it has considerable public health implications. Ethnic differences in OR for diabetes persisted after adjustment for age, adiposity, physical activity and education. These differences were still present for women after additional adjustment for body height and fertility.

Keywords Adiposity - Ethnicity · Diabetes prevalence (type 2) - Sex - Physical activity $\cdot$ Socio-economic South Asians

Abbreviations FSG: Fasting serum glucose - NFSG: Non-fasting serum glucose $\cdot$ OR: Odds ratio

\section{Introduction}

Several studies have demonstrated large ethnic differences in diabetes susceptibility, but the relative importance of environmental and genetic factors remains to be clarified. Reports from studies of European and Asian cohorts place the urban population from India at greatest risk, and different ethnic susceptibility according to age and BMI has been reported [1-3].

In Western societies, low socio-economic status is a risk factor for type 2 diabetes and cardiovascular disease, but the extent to which socio-economic status can explain ethnic differences in the prevalence of these diseases between migrants and the host population is still under discussion $[4,5]$. In recent years, only a few studies from Europe have focused on the associations between diabetes prevalence, ethnicity, modifiable lifestyle factors and socio-economic status $[5,6]$.

The aim of this investigation was to study the prevalence of diabetes in relation to ethnicity and sex, including known risk factors and socio-economic factors as possible confounders in the analyses. 


\section{Subjects and methods}

In $2000,6,140$ subjects aged $30-67$ years in two administrative districts with low socio-economic status in eastern Oslo were invited by letter to participate in a population-based survey containing a questionnaire with questions about general health status, self-reported disease, health-related behaviour and socio-economic factors (the letter contained brief information in several languages) [7]. The questionnaire was translated into relevant languages. Measurements of body height, weight, waist and hip circumferences, blood pressure and non-fasting serum glucose (NFSG) were performed according to established standards [7].

Known diabetes was based on self-reports. Subjects with NFSG levels above $6.0 \mathrm{mmol} / 1$ were requested to return within a few days for a fasting serum glucose (FSG) and $\mathrm{HbA}_{1} \mathrm{c}$, measured by HPLC (Variant; Bio-Rad, Richmond, CA, USA) with a normal reference range of $4.1-6.4 \%$. Subjects not reporting diabetes, but with FSG of $7.0 \mathrm{mmol} / \mathrm{l}$ or above, or $\mathrm{HbA}_{1} \mathrm{c}$ greater than $6.4 \%$, or NFSG of $11.1 \mathrm{mmol} / 1$ or higher and not attending for fasting venous samples, were categorised as having undiagnosed diabetes [7].

Self-reported leisure-time physical activity was assessed using two sets of questions on a four-point scale [7]. In the analyses the two categories for the highest levels of activity were merged for both variables. The questionnaire contained questions about food frequency and preferences for selected items, work participation and years of formal education $(\leq 9,10-12,>12$ years) [7]. The income variable was based on information from several registers, and contained three groups for annual net income as defined by Statistics Norway: low (<€18,000), medium (€ 18,000-24,000), and high $(>€ 24,000)$. Ethnicity was classified according to information on country of birth from Statistics Norway. A total of 2,950 persons (48\%) attended and gave written consent for the use of their data. Pregnant women $(n=17)$ and the non-South Asian immigrant group $(n=420)$ were excluded, the latter because of its heterogeneity, leaving 2,302 Westerners (Western Europe, North America, Australia and New Zealand), and 211 South Asians (Pakistan, $n=113$, India, $n=28$, Sri Lanka, $n=70$ ) in the study. Western men under 40 years of age had the lowest attendance rates. In both ethnic groups the non-attenders had slightly lower socio-economic status than the attenders. Further details about the methods, including a discussion of selection bias, have been reported earlier [7]. The Regional Ethics Committee and the Norwegian Data Inspectorate approved the study protocol.

Statistical analyses Chi square tests were used to assess differences in distributions between groups. For continuous variables, the mean and SD are given, and $t$-tests were performed to assess differences between groups. Diabetes prevalence and adiposity variables were age-standardised using the Norwegian population in 2000. The associations between diabetes and ethnicity, sex and other variables were calculated using logistic regression analyses, with diabetes as the dependent variable. Interactions were tested by performing chi square tests comparing log likelihood of the models with and without cross-product terms between two and two factors. For continuous variables, the regression
Table 1 Background factors in 30 - to 67 -year-olds by sex and ethnicity

Values are percentages unless stated otherwise

${ }^{\mathrm{a}} p<0.001$ vs men

${ }^{\mathrm{b}} p<0.001$ vs Western

${ }^{c} p<0.05$ vs Western

$\mathrm{d}_{p<0.05 \text { vs men }}$

\begin{tabular}{|c|c|c|c|c|c|c|c|c|}
\hline & \multicolumn{4}{|c|}{ Western $(n=2,302)$} & \multicolumn{4}{|c|}{ South Asians $(n=211)$} \\
\hline & $\begin{array}{l}\text { Women } \\
(n=1,322)\end{array}$ & SD & $\begin{array}{l}\text { Men } \\
(n=980)\end{array}$ & SD & $\begin{array}{l}\text { Women } \\
(n=90)\end{array}$ & SD & $\begin{array}{l}\text { Men } \\
(n=121)\end{array}$ & SD \\
\hline Attendance rates & $53.7^{\mathrm{a}}$ & & 44.3 & & 47.4 & & 50.0 & \\
\hline Age (years) mean (SD) & 48.6 & 9.7 & 49.7 & 10.1 & $41.9^{\mathrm{b}}$ & 8.2 & $43.1^{\mathrm{b}}$ & 8.5 \\
\hline Body height $(\mathrm{cm})$ mean $(\mathrm{SD})$ & $165.9^{\mathrm{a}}$ & 6.3 & 179 & 6.8 & $157.6^{\mathrm{ab}}$ & 5.8 & $169.5^{\mathrm{b}}$ & 6.6 \\
\hline $\begin{array}{l}\text { Fertility rate (number of children) } \\
\text { mean (SD) }\end{array}$ & 1.7 & 1.1 & & & $3.2^{\mathrm{b}}$ & 1.8 & & \\
\hline \multicolumn{9}{|l|}{ Socio-economic factors } \\
\hline Full-time job & $55.4^{\mathrm{a}}$ & & 78.1 & & $31.0^{\mathrm{ab}}$ & & 71.7 & \\
\hline Prevalence of low net income & $30.2^{\mathrm{a}}$ & & 17.2 & & $63.6^{\mathrm{ab}}$ & & $24.6^{\mathrm{c}}$ & \\
\hline Prevalence of high education & $34.9^{\mathrm{a}}$ & & 42.4 & & $30.6^{\mathrm{d}}$ & & 45.2 & \\
\hline Divorced or separated & 26.3 & & 18.4 & & $5.6^{\mathrm{b}}$ & & $2.5^{\mathrm{b}}$ & \\
\hline \multicolumn{9}{|l|}{ Behavioural factors } \\
\hline \multicolumn{9}{|c|}{ Physical inactivity - different variables } \\
\hline Sedentary leisure time subjects & $23.3^{\mathrm{a}}$ & & 32.5 & & $57.9^{\mathrm{b}}$ & & $57.0^{\mathrm{c}}$ & \\
\hline $\begin{array}{l}\text { No heavy physical activity in } \\
\text { leisure time }\end{array}$ & $40.7^{\mathrm{a}}$ & & 35.0 & & $64.0^{\mathrm{b}}$ & & $50.5^{\mathrm{b}}$ & \\
\hline \multicolumn{9}{|l|}{ Dietary habits } \\
\hline Full fat milk daily & 10.1 & & 10.9 & & $34.9^{\mathrm{b}}$ & & $36.1^{\mathrm{b}}$ & \\
\hline $\begin{array}{l}\text { Preference for soft drinks with } \\
\text { sugar vs without }\end{array}$ & $50.4^{\mathrm{a}}$ & & 66.9 & & $62.9^{\mathrm{bd}}$ & & $80.4^{\mathrm{c}}$ & \\
\hline Juice daily & $27.2^{\mathrm{d}}$ & & 22.7 & & $37.3^{\mathrm{c}}$ & & $36.4^{\mathrm{c}}$ & \\
\hline Fresh vegetables daily & $11.6^{\mathrm{a}}$ & & 6.7 & & $22.1^{\mathrm{c}}$ & & $14.2^{\mathrm{c}}$ & \\
\hline Daily smokers & $44.4^{\mathrm{a}}$ & & 35.6 & & $1.2^{\mathrm{ab}}$ & & $26.1^{\mathrm{c}}$ & \\
\hline
\end{tabular}


a

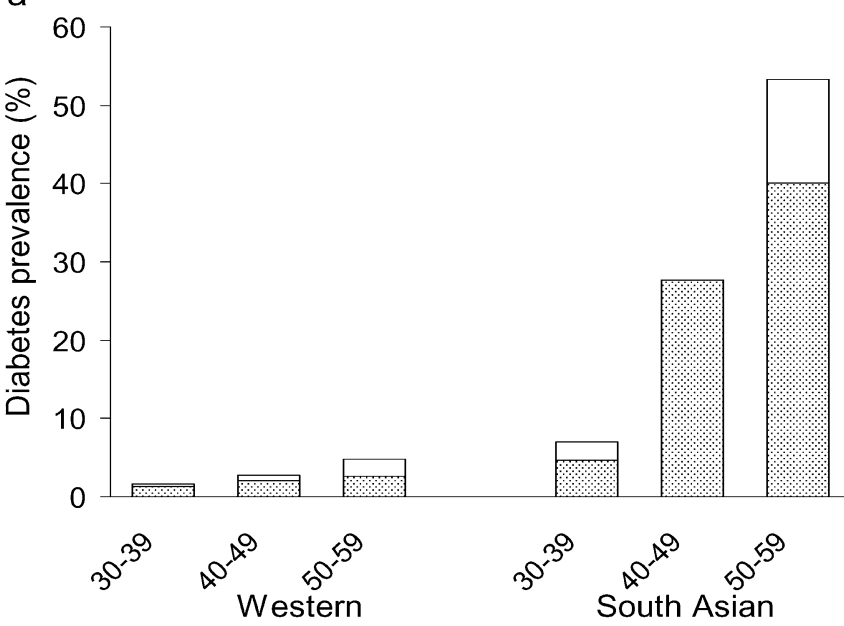

b

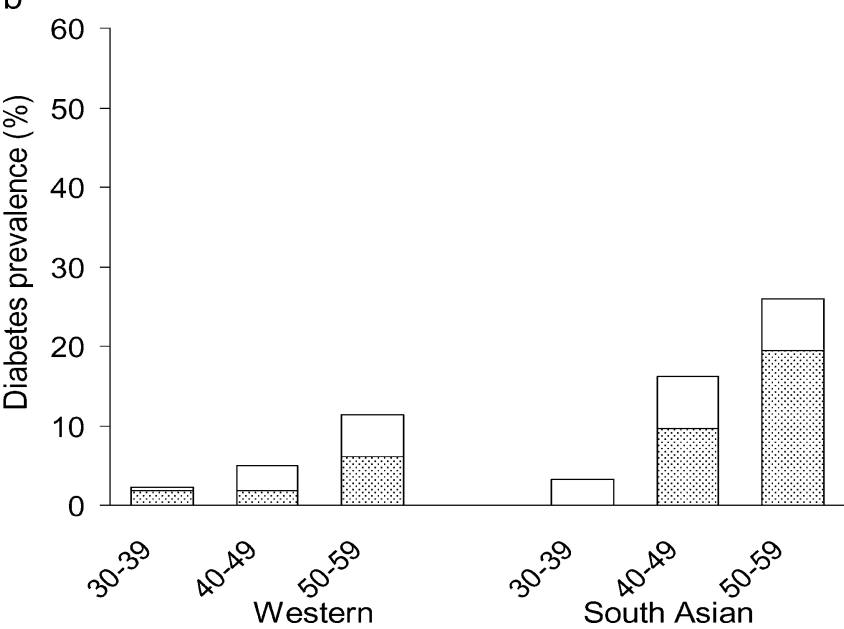

Fig. 1 Age-specific prevalence of known (hatched bars) and undiagnosed (open bars) diabetes by ethnicity in women (a) and men (b)

coefficients were standardised using the SD for the whole population for each variable. Differences in regression coefficients between groups were assessed using $z$-tests. A $p$ value of less than 0.05 was considered significant.

\section{Results}

Diabetes was reported by 103 of the 2,513 subjects studied, but the total number of subjects with diabetes was 170 when the cases detected in the survey were included. Nine of the subjects with known diabetes were diagnosed before the age of 25 years. The main characteristics of the populations are given in Table 1. The age-specific and sexspecific prevalence of diabetes differed markedly between the ethnic groups (Fig. 1), as did the age-standardised diabetes prevalence and adiposity variables (Table 2). For 30- to 67-year-olds, the age-standardised total diabetes prevalence was $3.3 \%(95 \% \mathrm{Cl}: 2.3-4.3)$ for Western women and $7.2 \%$ (95\% Cl:5.6-8.8) for Western men.

In the logistic regression analyses we found significant interactions for sex/ethnicity $(p<0.001)$, ethnicity/income $(p<0.01)$ and sex/income $(p<0.02)$. Sex-specific analyses were therefore first performed for each ethnic group. The regression coefficients differed according to sex and ethnicity (Table 3 ). We then assessed the impact of sex as such, as well as of the socio-economic factors, on diabetes prevalence within each ethnic group. Finally, we performed sex-specific analyses to identify the impact of ethnicity in different models, adjusting for risk factors and covariates.

The age-adjusted odds ratio (OR) for diabetes for women vs men was $1.9(95 \% \mathrm{Cl}: 0.9-4.1)$ for South Asians, and 0.4 $(95 \% \mathrm{Cl}: 0.3-0.6)$ for the Western population $(p<0.001)$. The ethnic difference was significant after additional adjustment for BMI (OR 1.5; 95\% Cl:0.7-3.4 vs 0.4; 95\% $\mathrm{Cl}: 0.3-0.6)$. Education was strongly negatively associated with diabetes among Westerners after adjusting for age. A similar tendency was found among South Asians (not significant). With increasing levels of income, a gradual reduction in OR for diabetes was observed for Western men and women. The sex/income interaction implied a significantly stronger impact of income for women than for men. In contrast, the association was positive among South Asians, making the ethnic difference for this variable statistically significant. When assessing the effect of income among the immigrants, as the sex/income interaction here was non-significant, the OR for diabetes adjusted for age and sex was $3.0(95 \% \mathrm{Cl}: 1.1-8.3)$ for the medium-vs the low-income group $(p=0.03)$, and $1.9(95 \% \mathrm{Cl}: 0.6-5.7)$ for

Table 2 Age-standardised diabetes prevalence (self-reported and total) and adiposity parameters for 30- to 59-year-olds

\begin{tabular}{|c|c|c|c|c|c|c|c|c|}
\hline & \multicolumn{4}{|l|}{ Western $(n=1,944)$} & \multicolumn{4}{|c|}{ South Asian $(n=205)$} \\
\hline & Women $(n=1,144)$ & $95 \% \mathrm{CI}$ & $\operatorname{Men}(n=800)$ & $95 \% \mathrm{CI}$ & Women $(n=87)$ & $95 \% \mathrm{CI}$ & Men $(n=118)$ & $95 \% \mathrm{CI}$ \\
\hline $\begin{array}{l}\text { Self-reported diabetes } \\
\text { prevalence }(\%)\end{array}$ & 2.0 & $1.2-2.8$ & 3.1 & $1.9-4.3$ & 22.7 & $13.9-31.5$ & 9.0 & $3.9-14.2$ \\
\hline $\begin{array}{l}\text { Total diabetes } \\
\text { prevalence }(\%)\end{array}$ & 2.9 & $1.9-3.9$ & 5.9 & $4.2-7.5$ & 27.5 & $18.1-36.9$ & 14.3 & $8.0-20.7$ \\
\hline BMI (mean) kg/m² & 26.1 & $25.9-26.4$ & 27.2 & $26.9-27.5$ & 28.5 & $27.5-29.6$ & 26.7 & $26.1-27.4$ \\
\hline $\mathrm{BMI}>30 \mathrm{~kg} / \mathrm{m}^{2}(\%)$ & 19.4 & $17.1-21.7$ & 21.2 & $18.3-24.0$ & 36.7 & $26.5-46.9$ & 17.0 & $10.2-23.7$ \\
\hline WHR (mean) & 0.80 & $0.79-0.80$ & 0.91 & $0.91-0.92$ & 0.85 & $0.83-0.87$ & 0.92 & $0.91-0.93$ \\
\hline
\end{tabular}

Norwegian population (men and women): $30-59$ years as standard. The age group 60-67 years was omitted due to small numbers of South Asians 
Table 3 Odds ratios (ORs) from logistic regression analyses with diabetes as dependent variable for Western and South Asian subjects by sex
ORs are standardised for continuous variables for one SD difference. Categorical variables are in three categories, and are analysed as categorical. All variables are age-adjusted. $z$ tests for differences in regression coefficients between ethnic groups were performed to test whether they are significant at the $p=0.05$ level

${ }^{\mathrm{a} B e t w e e n ~ W e s t e r n ~ a n d ~ S o u t h ~}$ Asian groups

${ }^{\mathrm{b}}$ WHR is multiplied by 10 before standardisation ${ }^{\mathrm{c}}$ Omitted due to small numbers

\begin{tabular}{|c|c|c|c|c|c|}
\hline & \multicolumn{2}{|c|}{ Western } & \multicolumn{2}{|c|}{ South Asian } & \multirow[t]{2}{*}{$p^{\mathrm{a}}$} \\
\hline & OR & $95 \% \mathrm{CI}$ & OR & $95 \% \mathrm{CI}$ & \\
\hline \multicolumn{6}{|l|}{ Women } \\
\hline Age & 1.64 & $1.59-1.69$ & 2.26 & $2.11-2.41$ & $<0.001$ \\
\hline \multicolumn{6}{|l|}{ Anthropometric variables } \\
\hline BMI & 1.67 & $1.59-1.76$ & 1.22 & $1.09-1.36$ & $<0.001$ \\
\hline $\mathrm{WHR}^{\mathrm{b}}$ & 2.49 & $1.76-3.50$ & 2.21 & $1.06-4.59$ & ns \\
\hline \multicolumn{6}{|l|}{ Leisure time physical activity variables } \\
\hline Sedentary (reference) & 1.0 & & 1.0 & & \\
\hline Active $<4 \mathrm{~h} /$ week & 1.01 & $0.50-2.05$ & 1.24 & $0.38-3.99$ & ns \\
\hline Active $>4 \mathrm{~h} /$ week & 0.55 & $0.12-2.56$ & $-^{\mathrm{c}}$ & & \\
\hline Heavy physical activity—no (reference) & 1.0 & & 1.0 & & \\
\hline Heavy physical activity: $<1 \mathrm{~h} /$ week & 0.68 & $0.31-1.50$ & 0.85 & $0.22-3.30$ & ns \\
\hline Heavy physical activity: $>1 \mathrm{~h} /$ week & 0.28 & $0.10-0.74$ & 0.56 & $0.10-3.13$ & ns \\
\hline Daily smoking (yes vs no) & 1.14 & $0.64-2.04$ & $-^{\mathrm{c}}$ & & \\
\hline \multicolumn{6}{|l|}{ Socio-economic factors } \\
\hline Net income-low-income group (reference) & 1.0 & & 1.0 & & \\
\hline Net income-medium-income group vs low & 0.28 & $0.14-0.57$ & 2.48 & $0.66-9.31$ & $<0.01$ \\
\hline Net income-high-income group vs low & 0.08 & $0.03-0.28$ & 1.61 & $0.35-7.34$ & $<0.01$ \\
\hline Years of education-low-education group (reference) & 1.0 & & 1.0 & & \\
\hline Years of education-medium-education group vs low & 0.53 & $0.27-1.03$ & 0.66 & $0.20-2.23$ & ns \\
\hline Years of education-high-education group vs low) & 0.33 & $0.14-0.78$ & 0.35 & $0.08-1.57$ & ns \\
\hline Body height $(\mathrm{cm})$ & 0.45 & $0.43-0.47$ & 1.18 & $1.08-1.30$ & $<0.001$ \\
\hline \multicolumn{6}{|l|}{ Men } \\
\hline Age & 1.98 & $1.93-2.03$ & 2.70 & $2.53-2.88$ & $<0.001$ \\
\hline \multicolumn{6}{|l|}{ Anthropometric variables } \\
\hline BMI & 1.86 & $1.77-1.96$ & 2.11 & $1.82-2.45$ & ns \\
\hline $\mathrm{WHR}^{\mathrm{b}}$ & 2.30 & $1.68-3.16$ & 3.95 & $1.40-11.17$ & ns \\
\hline \multicolumn{6}{|l|}{ Leisure time physical activity variables } \\
\hline Sedentary (reference) & 1.0 & & 1.0 & & \\
\hline Active $<4 \mathrm{~h} /$ week & 0.86 & $0.53-1.40$ & 1.38 & $0.40-4.79$ & ns \\
\hline Active $>4 \mathrm{~h} /$ week & 0.40 & $0.17-0.94$ & $-^{\mathrm{c}}$ & & \\
\hline Heavy physical activity—no (reference) & 1.0 & & 1.0 & & \\
\hline Heavy physical activity: $<1 \mathrm{~h} /$ week & 0.85 & $0.48-1.52$ & 0.41 & $0.08-2.19$ & ns \\
\hline Heavy physical activity: $>1$ h/week & 0.65 & $0.38-1.14$ & 1.40 & $0.30-6.56$ & ns \\
\hline Daily smoking (yes vs no) & 0.91 & $0.56-1.46$ & 0.70 & $0.17-2.81$ & ns \\
\hline \multicolumn{6}{|l|}{ Socio-economic factors } \\
\hline Net income-low-income group (reference) & 1.0 & & 1.0 & & \\
\hline Net income-medium-income group vs low & 0.52 & $0.28-0.96$ & 4.00 & $0.71-22.53$ & $<0.05$ \\
\hline Net income-high-income group vs low & 0.49 & $0.28-0.86$ & 2.46 & $0.39-15.38$ & ns \\
\hline Years of education-low-education group (reference) & 1.0 & & 1.0 & & \\
\hline Years of education-medium-education group vs low & 0.48 & $0.27-0.86$ & 1.56 & $0.31-7.91$ & ns \\
\hline Years of education - high-education group vs low) & 0.62 & $0.35-1.09$ & 0.99 & $0.18-5.35$ & ns \\
\hline Body height (cm) & 0.70 & $0.67-0.73$ & 0.85 & $0.79-0.93$ & $<0.001$ \\
\hline
\end{tabular}

the high-vs the low-income group. Physical activity was significantly inversely associated with diabetes for Westerners, but no significant association was found for South Asians.

In the sex-specific models, the age-adjusted OR for diabetes for South Asians vs Westerners was $11.0(95 \%$ $\mathrm{Cl}: 5.8-21.1)$ for women and $3.0(95 \% \mathrm{Cl}: 1.6-5.4)$ for men, and after adjustment for WHR the ORs were $7.7(95 \%$ $\mathrm{Cl}: 3.9-15.3)$ for women and $2.6(95 \% \mathrm{Cl}: 1.4-4.9)$ for men. The ethnic differences persisted at the same level after adjusting for heavy physical activity and/or education. In the fully adjusted model with age, WHR, education, physical activity and body height, the OR for diabetes for South Asian vs Western men was 1.9 (95\% Cl:0.9-4.0). However, for women the OR was $6.0(95 \% \mathrm{Cl}: 2.3-15.4)$ after similar adjustments and adjustments also for fertility rates.

\section{Discussion}

The observed diabetes prevalence of $7.2 \%$ in Western men is higher than reported in most studies from Europe [1], but 
is comparable to recent findings from a study in Denmark that also reported men as the sex at highest risk [8]. The proportion of previously undiagnosed diabetes was highest in men. Since OGTTs were not performed, the total diabetes prevalence is probably underestimated, particularly for Western women over 60 years of age [1]. Not surprisingly, the diabetes prevalence in the South Asian population is higher than in the host population, but for the women the prevalence is high even compared with reports from urban areas in the Indian subcontinent and from South Asian migrants to different continents [2,9]. Up until now, the sex difference in diabetes prevalence has been given little attention.

The trends in obesity development seem to affect Western men more than women, whereas women seem to be the most susceptible among South Asian migrants. The mean BMI for South Asian women was higher than reported in most studies of migrants to Europe, or from their country of origin [3]. Even though there may be problems with validity of the data when assessing physical activity using questionnaires, we found striking differences between the two populations studied. The dominant finding was the low level of physical activity among the South Asians. When the majority of people are obese or sedentary, the association of these factors with diabetes is probably underestimated. Different cultural norms about leisure-time physical activity probably exist. A cold climate possibly represents an extra barrier for immigrants to engage in outdoor physical activity. The South Asians seem to have a higher preference than Westerners for some energy-dense food items, and this may also contribute to the energy imbalance.

With attendance rates of $49.4 \%$ (Westerners) and $49.0 \%$ (South Asians) the possibility of selection bias exists. Subjects with low socio-economic status are slightly underrepresented in both groups [7]. Attendance rates in surveys in Norway have fallen markedly during the last few decades to even lower rates than in the present study, especially among low socio-economic status groups and among immigrants [10]. When studying the associations between disease and risk factors, however, the effect of selection bias will be less than when assessing prevalence estimates or population means of risk factors. However, the impact of the low attendance rate on the prevalence estimates of diabetes was considered to be of minor importance in a recent study, and they are probably underestimated rather than overestimated [10].

The associations between diabetes and education, income and body height among Westerners are strong, especially for women. The reverse effect of income on diabetes prevalence across the populations studied may be seen as a co-existence in time and space of sub-populations in different stages of the epidemiological transition of the diabetes epidemic. Height may serve as a proxy for ethnicity and genetic factors, but also for childhood socio-economic status. We have found only one small study of highly se- lected Europeans, in which the association of diabetes with present and past socio-economic factors, and adiposity and behavioural factors were assessed in the same model [6].

The different impact of sex in the two ethnic groups gives a strong indication of the importance of environmental influences, even when populations with high vs low susceptibility for diabetes are compared. Ethnic differences in sex roles, job participation and societal norms about obesity and physical fitness may be of importance. The very high diabetes prevalence in ethnic subgroups represents a new public health challenge in the Nordic countries. Culture-specific strategies made in cooperation with the immigrant communities should be designed and evaluated, to prevent a further increase in the future.

Acknowledgements The study was planned jointly by the Norwegian Institute of Public Health, the Norwegian University of Sport and Physical Education, the Aker/Ullevaal Diabetes Research Centre, and the local District Administrations and Councils. The data collection was performed and financed by the Norwegian Institute of Public Health, and the Norwegian Research Council financed the data analyses. We thank Bernadette Kumar for valuable comments on the manuscript.

\section{References}

1. DECODE Study Group (2003) Age- and sex-specific prevalences of diabetes and impaired glucose regulation in 13 European cohorts. Diabetes Care 26:61-69

2. Qiao Q, Hu G, Tuomilehto J et al (2003) Age- and sex-specific prevalence of diabetes and impaired glucose regulation in 11 Asian cohorts. Diabetes Care 26:1770-1780

3. Nakagami T, Qiao Q, Carstensen B et al (2003) Age, body mass index and type 2 diabetes - associations modified by ethnicity. Diabetologia 46:1063-1070

4. Nazroo JY, Davey Smith G (2001) The contribution of socioeconomic position to health differentials between ethnic groups: evidence from the United States and Britain. In: H Macbeth, P Shetty (eds) Health and ethnicity, 1st edn. Taylor \& Francis, London. pp 41-58

5. Bhopal R, Hayes L, White M et al (2002) Ethnic and socioeconomic inequalities in coronary heart disease, diabetes and risk factors in Europeans and South Asians. J Public Health Med. 24:95-105

6. Riste L, Khan F, Cruickshank K (2001) High prevalence of type 2 diabetes in all ethnic groups, including Europeans, in a British inner city: relative poverty, history, inactivity, or 21 st century Europe? Diabetes Care 24:1377-1383

7. Jenum AK, Lorentzen C, Anderssen SA et al (2003) Promoting physical activity in a multi-ethnic district - methods and baseline results of a pseudo-experimental intervention study. Eur J Cardiovasc Prev Rehabil 10:387-396

8. Glumer C, Jorgensen T, Borch-Johnsen K (2003) Prevalences of diabetes and impaired glucose regulation in a Danish population: the Inter99 study. Diabetes Care 26:2335-2340

9. Abate N, Chandalia M (2001) Ethnicity and type 2 diabetes: focus on Asian Indians. J Diabetes Complications 15:320-327

10. Søgaard AJ, Selmer R, Bjertness E, Thelle D (2004) The Oslo Health Study: the impact of self-selection in a large populationbased survey. Int J Equity Health 3:3 http://www.equityhealthj. $\operatorname{com} /$ content $/ 31 / 3$ 